\title{
Using Australian Pharmaceutical Benefits Scheme data for pharmacoepidemiological research: challenges and approaches
}

\section{Ellie Paige ${ }^{\mathrm{a}, \mathrm{d}}$, Anna Kemp-Casey ${ }^{\mathrm{b}}$, Rosemary Kordaa and Emily Banksª}

a National Centre for Epidemiology and Population Health, Research School of

Population Health, Australian National University, Canberra, ACT

b School of Population Health, University of Western Australia, Perth

c The Sax Institute, Sydney, NSW, Australia

d Corresponding author: ellie.paige@anu.edu.au

\section{Article history}

Publication date: September 2015

Paige E, Kemp-Casey A, Korda R, Banks E. Using Australian Pharmaceutical Benefits Scheme data for pharmacoepidemiological research: challenges and approaches. Public Health Res Pract. 2015;25(4):e2541546. doi: http://dx.doi. org/10.17061/phrp2541546

Key points

- Use of the Pharmaceutical Benefits Scheme (PBS) dataset for pharmacoepidemiological research presents a range of challenges, some of which are distinct from those of other administrative datasets

- Key issues that arise when using the PBS relate to accurate identification of medicine dispensings and how to define medicine exposure

- A variety of methodological approaches can be used to address these issues

\section{Abstract}

The Pharmaceutical Benefits Scheme (PBS) dataset provides detailed information about subsidised medicines dispensed in Australia and is increasingly used for pharmacoepidemiological research. Use of the PBS dataset provides unique opportunities for such research, but comes with its own set of challenges that must be considered and addressed. This paper outlines some issues that commonly arise when using PBS data - relating to accurate identification of medicine dispensings and how to define medicine exposure - and suggests some possible approaches for dealing with them. The paper is intended as an introductory resource for researchers.

\section{Introduction}

The Pharmaceutical Benefits Scheme (PBS) is an Australian Government program that provides residents with access to a wide range of subsidised prescription medicines. ${ }^{1}$ The scheme is managed by the Department of Health and administered by the Department of Human Services. The PBS dataset is the administrative record of medicines dispensed to individuals through the scheme. This dataset is increasingly used for research and has major advantages compared with self-reported information on medicines or clinical chart review. PBS data for particular studies can be requested and accessed by approved researchers; identifiers are removed from records to protect consumer privacy. A $10 \%$ random sample of the Australian population's PBS data is also available to the medicines industry and other research groups. ${ }^{2}$

The PBS dataset captures community-based dispensings of prescription medicines subsidised by the Australian Government. However, in general terms, it does not capture information on medicines supplied by nonapproved pharmacies or hospitals ${ }^{3}$, private prescriptions (for medicines not listed on the PBS), over-the-counter medicines, and medicines covered under schemes 
such as the Repatriation Pharmaceutical Benefits Scheme, which provides access to subsidised medicines for veterans. ${ }^{4}$

The PBS dataset provides detailed information about prescription and dispensing dates, and medicine name and strength. However, there are challenges in using these data for pharmacoepidemiological studies, which arise because the dataset was not designed for research purposes. These include accurate identification of dispensing of medicines, and how to define medicine exposure. These issues and some suggested approaches for dealing with them are the focus of this paper. The challenges discussed are in relation to individual-level PBS data, but many of these challenges and possible approaches also apply to aggregate-level data, such as those publicly available online from the Department of Human Services. ${ }^{5,6}$

There are many ways to address the issues identified in this paper, and we provide some suggested approaches with examples from recent research using PBS data. The paper is divided into two parts: part one examines issues and possible solutions for identifying medicine dispensings from the PBS data, and part two focuses on ways to define medicine exposure, including approaches to defining use and dose.

\section{Part one: identifying medicine dispensings}

A first step in pharmacoepidemiological analysis using PBS data is identifying what medicines have been dispensed to individuals. There are four key issues to consider: identification of individuals, completeness of data capture, changes in beneficiary status over time, and changes in medicines listed on the PBS.

\section{Identifying which individuals were dispensed medicines}

Access to medicines under the PBS is available to Australian residents who hold a current Medicare card and people from countries with a reciprocal healthcare agreement. ${ }^{4}$ Australian and New Zealand citizens, and people with a permanent Australian visa are eligible for Medicare cards. ${ }^{7}$ Before May 2002, PBS dispensings were attributed to the individual listed as number 1 on the Medicare card presented, irrespective of which individual was named on the script. This means that for this time period, there is potential for misattribution of the patient's identity whenever multiple individuals were listed on a Medicare card, as is often the case for couples and families. Consequently, the dataset may incorrectly link unrelated scripts to the same individual before May 2002. Since 2002, PBS dispensings have been attributed to the person listed on the script, regardless of the number they have listed on their Medicare card.
This issue does not cause problems for researchers examining aggregate dispensing trends (i.e. at the population level) but does affect the accuracy of individual-level analyses. If individual-level analyses are needed (i.e. the researcher wishes to be certain that the medicines listed for a person were dispensed to that person), the only solution is to exclude dispensing records before May 2002.

\section{Incomplete data capture}

For medicines listed on the PBS, consumers pay a copayment towards the cost, with the remainder paid by the Australian Government through the PBS. People with eligible concession cards ('concessional beneficiaries') pay a smaller copayment ( $\$ 6$ in 2014) than the rest of the population ('general beneficiaries'; $\$ 36.90$ in 2014). ${ }^{8}$ Concessional benefits are available to people with a Pensioner Concession Card, a Commonwealth Seniors Health Card or a Health Care Card. ${ }^{8}$

Before July 2012, PBS data did not include dispensings for medicines that fell below the consumer copayment level. No medicines cost less than the concessional copayment, so all medicines dispensed to concessional beneficiaries were captured; however, many dispensings to general beneficiaries fell below the copayment level and were excluded from data capture. From July 2012 onwards, information on all PBS dispensings (including those that cost less than the consumer copayment level) is captured in the PBS database. Table 1 shows an example - using selective serotonin reuptake inhibitors - of whether a medicine would be captured in the PBS dataset before and after July 2012, depending on the cost of the medicine and the copayment level.

A further issue is that the PBS includes a safety net to limit the amount spent on medicines by individuals or families. ${ }^{8}$ Once the safety net threshold (\$360 for concessional beneficiaries and $\$ 1421$ for general beneficiaries in 2014) has been reached in a particular calendar year, concessional beneficiaries receive subsequent PBS medicines for free, and general beneficiaries pay the concessional copayment amount, for the rest of that year. This means that medicine records for general beneficiaries who reach the safety net may appear to be complete (i.e. some general beneficiary items for medicines below the copayment will appear), but there will be gaps in these data over the year before the safety net is reached. The same safety net threshold applies to families and individuals, and medicines dispensed at community and outpatient hospital pharmacies contribute towards it. ${ }^{8}$

When using PBS data for pharmacoepidemiological research, the PBS schedules should be checked to identify whether the medicine of interest is listed on the PBS. To determine whether the medicine of interest will be listed in the PBS dataset for all participants in the study population, it is important to check the costs of the 
Table 1. Summary of selective serotonin reuptake inhibitors listed on the PBS in 2014 , corresponding maximum price to the consumer, and whether the medicine would be captured in the PBS dataset before and after July 2012

\begin{tabular}{|c|c|c|c|c|c|c|c|c|}
\hline \multirow[b]{2}{*}{$\begin{array}{l}\text { Antidepressant } \\
\text { medicine }\end{array}$} & \multirow[b]{2}{*}{ ATC code } & \multirow{2}{*}{$\begin{array}{l}\text { PBS } \\
\text { item } \\
\text { code }\end{array}$} & \multirow[b]{2}{*}{ DDD } & \multirow{2}{*}{$\begin{array}{l}\text { Maximum } \\
\text { price to } \\
\text { consumer }(\$)^{a}\end{array}$} & \multicolumn{2}{|c|}{$\begin{array}{l}\text { Captured in PBS dataset } \\
\text { before July } 2012^{b}\end{array}$} & \multicolumn{2}{|c|}{$\begin{array}{l}\text { Captured in PBS dataset } \\
\text { from July } 2012 \text { onwards }\end{array}$} \\
\hline & & & & & $\begin{array}{l}\text { Concessional } \\
\text { beneficiaries }\end{array}$ & $\begin{array}{c}\text { General } \\
\text { beneficiaries }\end{array}$ & $\begin{array}{l}\text { Concessional } \\
\text { beneficiaries }\end{array}$ & $\begin{array}{c}\text { General } \\
\text { beneficiaries }\end{array}$ \\
\hline $\begin{array}{l}\text { Fluoxetine } \\
20 \text { mg capsule }\end{array}$ & N06AB03 & $1434 \mathrm{~L}$ & 1 & 19.29 & $\checkmark$ & $x$ & $\checkmark$ & $\checkmark$ \\
\hline $\begin{array}{l}\text { Fluvoxamine } \\
100 \text { mg tablet }\end{array}$ & N06AB08 & $8174 \mathrm{~F}$ & 1 & 24.67 & $\checkmark$ & $x$ & $\checkmark$ & $\checkmark$ \\
\hline $\begin{array}{l}\text { Citalopram } \\
40 \mathrm{mg} \text { tablet }\end{array}$ & N06AB04 & $8703 C$ & 2 & 17.80 & $\checkmark$ & $x$ & $\checkmark$ & $\checkmark$ \\
\hline $\begin{array}{l}\text { Escitalopram } \\
20 \mathrm{mg} \text { tablet }\end{array}$ & N06AB10 & $8701 Y$ & 2 & 17.99 & $\checkmark$ & $x$ & $\checkmark$ & $\checkmark$ \\
\hline $\begin{array}{l}\text { Escitalopram } \\
10 \mathrm{mg} / \mathrm{mL} \text { oral } \\
\text { liquid }\end{array}$ & N06AB10 & $8849 \mathrm{R}$ & 1 & 36.90 & $\checkmark$ & $\checkmark$ & $\checkmark$ & $\checkmark$ \\
\hline $\begin{array}{l}\text { Paroxetine } \\
20 \text { mg tablet }\end{array}$ & N06AB05 & $2242 B$ & 1 & 18.64 & $\checkmark$ & $x$ & $\checkmark$ & $\checkmark$ \\
\hline $\begin{array}{l}\text { Sertraline } \\
100 \mathrm{mg} \text { tablet }\end{array}$ & N06AB06 & $2237 \mathrm{R}$ & 2 & 15.50 & $\checkmark$ & $x$ & $\checkmark$ & $\checkmark$ \\
\hline
\end{tabular}

ATC = Anatomical Therapeutic Chemical; DDD = defined daily dose; PBS = Pharmaceutical Benefits Scheme

a The maximum price to the consumer is the highest price the consumer can be charged for a medicine. For general beneficiaries, this maximum price will not be above the general beneficiary copayment ( $\$ 36.90$ in 2014 ), except if there is a brand premium surcharge or a special patient contribution. ${ }^{4}$

b Copayment amounts at 1 July 2012: concessional beneficiaries $\$ 5.80$; general beneficiaries $\$ 35.40$.

Note: Information is based on 2014 prices (www.pbs.gov.au). Copayment amounts in 2014 were $\$ 6$ for concessional beneficiaries and $\$ 36.90$ for general beneficiaries. Where multiple medicine strengths were available for the same medicine and these had the same maximum price to the consumer, only one strength is listed in the table.

medicine over the study period and the corresponding general beneficiary copayment amounts. The price of the medicine can be checked by searching the appropriate historical PBS schedules ${ }^{9}$, and the relevant beneficiary copayment amounts and safety net limits. ${ }^{10}$ A suggested approach for determining whether analyses should be restricted to concessional-only beneficiaries is given in Figure 1.

\section{Changes in beneficiary status}

In the PBS dataset, a person's beneficiary status is listed against each dispensed medicine record; however, an individual's beneficiary status may change over time. A person may be a concessional beneficiary at one point but a general beneficiary at another, and this status can change multiple times. This is less of an issue for aged pension beneficiaries, who are unlikely to change status, but may be a problem if the study population includes a large proportion of low-income earners (e.g. students), whose eligibility may change as their income varies.

If analyses are restricted to concessional-only beneficiaries, it is necessary to decide how to deal with varying beneficiary status. There are two main ways of addressing this: changes in status can be ignored, or people who have only concessional beneficiary
Figure 1. Flowchart for determining which PBS beneficiaries can be included in analyses

Identify the study period of interest

Review the PBS schedules to check that the medicine was listed on the PBS for the entire study period. If not, consider restricting your analysis to a time period in which the medicine was available under the PBS.

The PBS schedules can be searched using the medicine name or PBS item code.

Check the cost of the medicine across the study period (by looking up cost to the consumer on the PBS website) and compare this with the general beneficiary copayment for the years of interest.

Does the medicine cost less than the general beneficiary copayment during at least some of the study period?

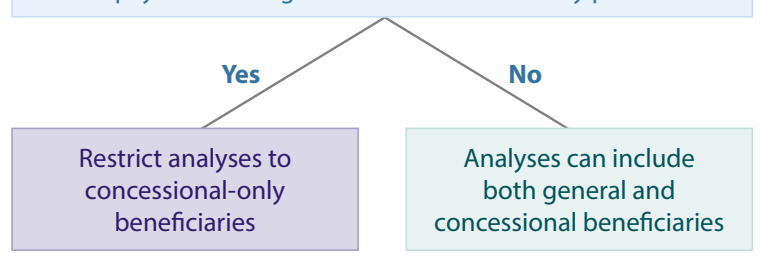


dispensings and no general beneficiary dispensings during the entire study period can be included in the analysis.

The approach to dealing with varying beneficiary status will depend on the study period and population, and the research question. For example, for studies with a short follow-up period, it may be decided that the changes in beneficiary status are minimal and can be ignored. For studies of medicines mainly used by older people (such as for Alzheimer's disease), it may be suitable to restrict analyses to people who have only concessional beneficiary dispensings and no general beneficiary dispensings.

\section{Changes in medicines listed on the PBS}

Each medicine and strength listed on the PBS has its own item code that can be used to identify specific dispensings. However, medicines subsidised by the PBS change over time, with some added and others removed.

PBS schedules of approved medicines are updated every month. It is important to check the historical PBS schedules for the relevant study period to verify whether the medicine of interest was listed on the PBS for the entire study period. Because PBS items can be listed and delisted depending on the PBS status of the medicine, it is worthwhile identifying medicine dispensings based on the Anatomical Therapeutic Chemical (ATC) code, listed in addition to the PBS item code in the PBS dataset. ATC codes were developed by the World Health Organization Collaborating Centre for Drug Statistics Methodology and are based on the body system in which the medicine acts, as well as its therapeutic action. ${ }^{11}$ These codes are substantially more stable than PBS item codes and are unchanged by listing status or strength variations. For example, in Table 1, the two different forms of escitalopram have different PBS item codes but the same ATC code. ATC codes occasionally change when the main use of a medicine is modified. For example, simvastatin was changed from a blood-acting agent to a cardiovascular agent in 1994. ${ }^{12}$

\section{Part two: defining medicine exposure}

The PBS dataset provides information on which medicines were dispensed, but does not provide information about scripts that were written by a doctor but not filled by the consumer, or about whether the consumer used the dispensed medicine. Furthermore, although dose is commonly examined in pharmacoepidemiology research, PBS data do not provide information on the indication for which the medicine was prescribed or the intended dose. The strength (and pack size) of the medicine is provided in the PBS data and can be used in different ways to define dose. This section outlines some approaches to defining medicine use and dose.

\section{Defining medicine use based on dispensings}

The key point to remember when defining medicine use is that PBS data capture medicine dispensings. Defining medicine use based on dispensing data depends on the outcome of interest and the research question being addressed. Input from clinicians is essential for deciding what constitutes 'use'. For some studies ${ }^{13,14}$, one or more medicine dispensings to an individual may be considered sufficient to define use. In other studies (e.g. Paige et al. ${ }^{15}$ ), there may be concerns that the medicine has been dispensed but not used by the consumer - this may be the case for medicines such as antidepressants, for which treatment adherence is low. In such studies, two or more dispensings of a medicine in a particular time period may be needed to define use.

Where aggregate rather than individual-level PBS data are available, the definitions of use mentioned above cannot be used. In this scenario, it is often more useful to discuss population-level medicine use, using the number of defined daily doses (DDD) dispensed per 1000 people per day. DDDs were developed by the World Health Organization for comparing drug use in drug utilisation studies, and are assigned to each ATC code. ${ }^{16}$ The DDD is "the assumed average maintenance dose per day for a drug used for its main indication in adults". ${ }^{16}$ For example, 20 mg of fluoxetine or citalopram are both considered to be one DDD. ${ }^{17}$ Thus, people dispensed fluoxetine $20 \mathrm{mg}$ tablets are receiving one DDD per tablet, while those dispensed citalopram $40 \mathrm{mg}$ tablets are receiving two DDD per tablet (Table 1). DDDs are often used to measure the number of 'standard' doses being dispensed to a population in a particular time frame, allowing comparisons between populations. For example, an Organisation for Economic Co-operation and Development (OECD) report estimated that 89 DDDs of antidepressants were dispensed per 1000 people per day in Australia in 2011, higher than the OECD average of 56 DDD per 1000 people per day in the same year. ${ }^{18}$

The approaches to defining medicine use should be decided by the researcher in the context of the research question, and with advice from clinicians and consumers. ${ }^{19}$ Methods used to analyse PBS data, and any assumptions underpinning definitions, should be explicitly outlined in research papers.

\section{Defining dose}

The PBS does not provide information on intended dose, and the intended dose or amount actually taken by the individual may change over time. In some circumstances, researchers may wish to compare outcomes between individuals where different doses of a medicine are used. Using PBS data, there are different ways to approximate the dose of a medicine used by a person. First, if it can be assumed that one tablet of a medicine is used per day, then the pack size of the medicine equals the number of days supplied. Under this assumption, the dose of the medicine used each day will equal the medicine's 
strength as listed on the PBS. Second, the mean number of DDDs dispensed to an individual can be calculated over time. The advantage of this method is that doses can be summed over time, even if there is a change in the strength of medicine dispensed or gaps in treatment. This can be done by identifying the DDD for each relevant ATC code and combining it with PBS data on the strength of the dispensed medicine to determine the number of DDDs dispensed for each person. DDDs per dispensing can be calculated as the strength $(\mathrm{mg})$ of the dispensed medicine multiplied by the pack size (number of tablets) divided by the DDD. The DDD dispensed per day can then be categorised - for example, to examine those dispensed $\leq 1$ DDD per day and those dispensed $>1$ DDD per day.

An advantage of looking at DDDs dispensed per day compared with the first approach is that DDD takes into account the relative strengths of medicines and thus allows comparisons across different medicines. In contrast to the DDD, the actual daily dose prescribed to consumers reflects diverse factors, including the indication for which the medicine was prescribed, the severity of the condition and patient characteristics. ${ }^{20}$ As a result, the DDD does not always reflect the prescribed dose, and it has been shown that the ratio of the prescribed daily dose to the DDD can vary widely between drug classes. ${ }^{20}$ This should be considered when planning analyses and interpreting results based on the DDD. The research question of interest and clinical input should guide the decision on how to approximate the dose of a medicine used by an individual. Clinical involvement in defining the approach is particularly important when there is a need to distinguish between low and high doses, because this will depend on the specific medicine of interest.

\section{Conclusion}

The PBS is an invaluable dataset for pharmacoepidemiological research in Australia, but it presents challenges when used for research purposes, particularly relating to identifying medicine dispensings and medicine exposure. In this paper, we outlined several possible design and methodological approaches that can be used to address these issues. However, every research study will be different, and clinical input at the research design and interpretation stages is vital for navigating these challenges and identifying appropriate strategies to deal with them.

\section{Acknowledgements}

EP is supported by an Australian Postgraduate Award. EB is supported by the National Health and Medical Research Council of Australia (NHMRC). The research was also supported by the NHMRC Centre of Research
Excellence in Medicines and Ageing (ID: 1060407) and NHMRC project grant number 1024450.

\section{Competing interests}

None declared

\section{Author contributions}

All authors contributed to the writing of this manuscript.

\section{References}

1. Duckett SJ. Drug policy down under: Australia's pharmaceutical benefits scheme. Health Care Financ Rev. 2004;25(3):55-67.

2. Department of Health. Sources of epidemiological data for use in generating utilisation estimates 2015. Canberra: Commonwealth of Australia; [cited 2015 Aug 20]. Available from: www.pbs.gov.au/info/industry/usefulresources/sources

3. Department of Health. Supplying medicines what pharmacists need to know 2015. Canberra: Commonwealth of Australia; 2015 [cited 2015 Aug 20]. Available from: www.pbs.gov.au/info/healthpro/ explanatory-notes/section1/Section_1_3_Explanatory_ Notes

4. Department of Health. PBS frequently asked questions. Canberra: Commonwealth of Australia; 2014 [cited 2014 Nov 24]. Available from: www.pbs.gov.au/info/ general/faq

5. Department of Human Services. Medicare item reports. Canberra: Australian Government; 2015 [cited 2015 Jan 29]. Available from: http://medicarestatistics. humanservices.gov.au/statistics/mbs_item.jsp

6. Department of Health. PBS and RPBS section 85 date of processing and date of supply data. Canberra: Commonwealth of Australia; 2015 [cited 2015 Aug 20]. Available from: www.pbs.gov.au/info/statistics/dos-anddop/dos-and-dop

7. Department of Human Services. Eligibility for Medicare card. Canberra: Australian Government; 2013 [cited 2014 Apr 11]. Available from: www.humanservices.gov. au/customer/enablers/medicare/medicare-card/eligibilityfor-medicare-card

8. Department of Health. About the PBS. Canberra: Commonwealth of Australia; 2015 [cited 2015 Aug 20]. Available from: www.pbs.gov.au/info/about-the-pbs

9. Department of Health. PBS publications. Canberra: Commonwealth of Australia; 2015 [cited 2015 Aug 20]. Available from: www.pbs.gov.au/browse/publications

10. Department of Health. Fees, patient contributions and safety net thresholds. Canberra: Commonwealth of Australia; 2015 [cited 2015 Aug 20]. Available from: www. pbs.gov.au/info/healthpro/explanatory-notes/front/fee 
11. WHO Collaborating Centre for Drug Statistics Methodology. ATC structure and principles. Oslo: World Health Organization; 2011 [cited 2014 Mar 13]. Available from: www.whocc.no/atc/structure_and_principles/

12. WHO Collaborating Centre for Drug Statistics Methodology. ATC alterations from 1982-2015. Oslo: World Health Organization; 2014 [cited 2015 Jan 29]. Available from: www.whocc.no/atc_ddd_alterations_ cumulative/atc_alterations/

13. Kemp A, Preen DB, Saunders C, Boyle F, Bulsara M, Malacova E, Roughhead EE. Early discontinuation of endocrine therapy for breast cancer: who is at risk in clinical practice? SpringerPlus. 2014;3:282.

14. Pratt NL, Ramsay EN, Kemp A, Kalisch-Ellett LM, Shakib S, Caughey GE, et al. Ranibizumab and risk of hospitalisation for ischaemic stroke and myocardial infarction in patients with age-related macular degeneration: a self-controlled case-series analysis. Drug Saf. 2014;37(12):1021-7.

15. Paige E, Korda RJ, Kemp A, Rodgers B, Banks E. Characteristics of antidepressant medication users in a cohort of mid-age and older Australians. Aust N Z J Psychiatry. 2015;49(3):275-90.
16. WHO Collaborating Centre for Drug Statistics Methodology. Guidelines for ATC classification and DDD assignment 2013. Oslo: World Health Organization; 2012 [cited 2015 Aug 20]. Available from: www.whocc.no/ filearchive/publications/1_2013guidelines.pdf

17. WHO Collaborating Centre for Drug Statistics Methodology. DDD definition and general considerations: World Health Organization; 2009 [cited 2014 Mar 13]. Available from: www.whocc.no/ddd/definition_and_ general_considera/

18. Organisation for Economic Co-operation and Development. Health at a Glance 2013: OECD indicators. Paris: OECD Publishing; 2013 [cited 2015 Aug 20]. Available from: www.oecd.org/els/health-systems/Healthat-a-Glance-2013.pdf

19. The University of Western Australia. Involving people in research. Perth: The University of Western Australia; 2015 [cited 2015 Aug 20]. Available from: www. involvingpeopleinresearch.org.au/

20. Grimmsmann T, Himmel W. Discrepancies between prescribed and defined daily doses: a matter of patients or drug classes? Eur J Clin Pharmacol. 2011;67(8):847-54.

\section{Copyright: (c) (i) (2)}

(C) 2015 Paige et al. This article is licensed under the Creative Commons Attribution-NonCommercial-ShareAlike 4.0 International Licence, which allows others to redistribute, adapt and share this work non-commercially provided they attribute the work and any adapted version of it is distributed under the same Creative Commons licence terms. See: www.creativecommons.org/licenses/by-nc-sa/4.0/ 